\title{
Geoprocessamento aplicado à análise do balanço hídrico e na determinação das chuvas necessárias para a inundação de uma represa na bacia do ribeirão Itaim, Taubaté, SP
}

\author{
Luciano Aparecido dos Santos로 Nelson Wellausen Dias² e Marcelo dos Santos Targa² \\ ${ }^{1}$ Universidade de Taubaté - UNITAU \\ Estrada Mun. Dr. José Luiz Cembranelli, 5.000-12080-010 - Taubaté - SP, Brasil. \\ \{luciano.eng.amb; nwdias; targa.Marcelo\}@gmail.com
}

\begin{abstract}
Building a dam not only contributes to supplying water to an urban population but also to provide means of improving river flow control and reducing river channel sedimentation, if correctly planned. This article presents the results of a study aimed at determining the amount of precipitation needed to fill a dam area based on existing GIS information and water balance research of the study area. Based on a prospective dam could be built in the Itaim creek basin in the municipality of Taubaté, SP, GIS analysis were conducted utilizing SPRING (a free GIS package) and compared to water balance results published previously. The results indicate that it would be necessary 449 days of rain in order to fill this dam area.
\end{abstract}

\section{INTRODUÇÃO:}

De acordo com o Plano de Bacias Hidrográficas do Rio Paraíba do Sul (2000), o Rio Paraíba do Sul é formado pela confluência dos rios Paraibuna e Paraitinga. Nasce no estado de São Paulo a cerca de $20 \mathrm{~km}$ em linha reta do Oceano Atlântico e percorre cerca de $900 \mathrm{~km}$ antes de desembocar no mesmo Oceano, em Atafona, distrito do município de São João da Barra, no estado do Rio de Janeiro. Este rio atravessa três estados e ainda serve por cerca de $100 \mathrm{~km}$ de divisa entre os estados de Minas Gerais e Rio de Janeiro.

Da Serra da Bocaina, nos municípios de Areias e São José do Barreiro, a 1800m de altitude, desce o rio Paraitinga rumo a sudoeste em vale estreito e encaixado entre a Serra do Mar e as Serras da Bocaina, Quebra-Cangalha e Jambeiro. Em vale aproximadamente paralelo ao primeiro, a partir do município de São Luis do Paraitinga, desce o rio Paraibuna (SP) até encontrarem-se próximos à cidade de mesmo nome, dando origem assim ao rio Paraíba do Sul.

Ainda segundo o Plano de Bacias (2000) observa-se que o rio Paraíba do Sul após percorrer alguns quilômetros, inverte o sentido de seu escoamento em aproximadamente $180^{\circ}$ ao encontrar os maciços graníticos da Serra da Guararema, passando a adotar o rumo nordeste, caminhando entre as Serras do Mar e da Mantiqueira até a foz. O Plano de Bacias (2000) apontou que os maiores afluentes do rio Paraíba do Sul, se localizam na margem esquerda e provêm do estado de Minas Gerais, mas no trecho paulista, os maiores afluentes, além dos formadores são: Jaguari, Una, Buquira/Ferrão, Embau/ Piquete, Bocaina, Iataguaçaba/ Pitangueiras.

Geograficamente, a bacia do rio Una localiza-se na margem direita do rio Paraíba do Sul. As altitudes deste território oscilam entre 500 a $1000 \mathrm{~m}$, sendo que a Serra do Quebra Cangalha encontra-se a nordeste e a Serra de Jambeiro a sudeste. Conforme Batista et al. (2005) a área total dessa bacia hidrográfica é de aproximadamente $476 \mathrm{~km}^{2}$, sendo que desses 86\% ficam no município de Taubaté, 8\% em Tremembé e 8\% em Pindamonhangaba.

Santos (2003) observou que a cabeceira do rio Una fica no córrego do Pinga, que é próximo às divisas dos municípios de Taubaté, Lagoinha, Pindamonhangaba e Roseira. Considerou-se o córrego como nascente do Una por possuir a nascente mais alta, aproximadamente $1430 \mathrm{~m}$ de altitude, e também por ser o formador mais distante da foz, que se encontra no Rio Paraíba do Sul. 
Grande parte das águas do Una é usada para abastecimento da população e para irrigação e uma parte menor é usada por indústrias.

O Relatório Final do Plano de Bacias do rio Paraíba do Sul, elaborado pelo CPTI (2000) aponta a relevância da bacia do rio Una, visto que a mesma foi hierarquizada como a $4^{\mathrm{a}}$ bacia em termos de prioridade para ações de recuperação da qualidade e quantidade.

Ainda segundo o Plano, a bacia do rio Una encontra-se ambientalmente protegida por vários diplomas federais, que em determinada porção do território se sobrepõem. Dentre tantos se destacam os seguintes documentos:

- CONAMA, Resolução nº 303 de 20 de março de 2002. Dispõe sobre

Parâmetros, definições e limites de Áreas de Preservação Permanente, 2002.

- Lei $n^{\circ}$. 7754, de 14/04/1989. Área de Preservação Permanente - Nascente dos Rios. Estabelece medidas para a proteção de florestas existentes nas nascentes dos rios e dão outras providências.

- Decreto ño 87.561 de 13/09/1982. Rio Paraíba do Sul - dispõe sobre medidas de recuperação e proteção ambiental da bacia hidrográfica da bacia hidrográfica do rio Paraíba do Sul.

Dentro da bacia hidrográfica do rio Una existem outras sub-bacias como a do Ribeirão Itaim, do Ribeirão das Antas, do Ribeirão Sete Voltas e outras.

Neste trabalho emprega-se a tecnologia de SIG - Sistema de Informação Geográfica como ferramenta para a realização de um estudo ambiental em bacia hidrográfica. Em específico foi desenvolvido um estudo de caso com base na implantação de uma barragem na sub-bacia do ribeirão Itaim, tributário do rio Una e avaliado o balanço hídrico de Taubaté para a construção dessa represa na sub-bacia do rio Una. Dessa forma foi possível calcular o volume hídrico necessário para o preenchimento da área da represa.

Sabe-se que a construção de uma barragem gera muitos impactos ambientais, porém, os benefícios podem ser significativos. Dessa forma, o impacto ambiental gerado pela construção da barragem deve ser amenizado com medidas preservacionistas e compensatórias.

É relevante lembrarmos que a água desempenha um papel fundamental no desenvolvimento socioeconômico de qualquer sociedade. Sua disponibilidade em quantidade e qualidade compatíveis com a demanda é um dos fatores que determinam o nível de qualidade de vida em um agrupamento humano (CARVALHO, 1994). Este é um dos fatores que induzem a construção de barragens. No município de Taubaté-SP está previsto no Plano Diretor a construção de quatro barragens na bacia hidrográfica do rio Una (PMT, 2006), com o objetivo de regularizar a vazão do rio e conter o assoreamento.

Esse trabalho reproduz a implantação da represa, por meio de um banco de dados georreferenciados, as condições topográficas da área e as restrições legais derivadas do Código Florestal (BRASIL, 1965) e Resoluções CONAMA 302 e 303/2002, além da cobertura do solo (BATISTA et, al. 2005), na área de estudo. Os resultados obtidos podem subsidiar os esforços de minimização dos impactos decorrentes da implantação do empreendimento, bem como, o planejamento de ações de mitigação desses impactos.

\section{OBJETIVOS}

O objetivo deste presente trabalho é avaliar o balanço hídrico de Taubaté para a construção de uma represa na sub-bacia do ribeirão Itaim, tributário do rio Una e calcular o volume hídrico necessário para o preenchimento dessa represa. 


\section{MATÉRIAIS E MÉTODOS}

\subsection{LOCALIZAÇÃO DA ÁREA DE ESTUDO}

Geograficamente, a bacia do rio Una localiza-se na margem direita do rio Paraíba do Sul. As altitudes deste território oscilam entre 500 a 1000 metros, sendo que a Serra do Quebra Cangalha encontra-se a nordeste e a Serra de Jambeiro a sudeste. A área de contribuição para a barragem está contida dentro da sub-bacia do ribeirão Itaim, tributário do rio Una, na região do Vale do Paraíba do Sul, localizada no leste do estado de São Paulo, entre a Serra da Mantiqueira e a Serra do Mar. A bacia do rio Una é formada pela união do ribeirão das Almas com o rio da Rocinha e seus afluentes (Itaim, ribeirão das Pedras ou Ipiranga, ribeirão das Sete Voltas, rio das Antas, ribeirão do Registro, e demais tributários da bacia), perfazendo uma área de $476 \mathrm{~km}^{2}$. A sub-bacia do ribeirão Itaim que contribui para a barragem tem uma área de $2,5 \mathrm{~km}^{2}$, e está compreendida pelo quadrante de coordenadas UTM (Zona 23, S) E: 442876,14, N: 7445007,94 e E: 443390,89, N: 7440562,09, E: 440317,69, N: 7439786,87. O tipo de solos presentes na área total da bacia do rio Una, de acordo com Batista et al. (2005) são: Latossolo Vermelho Amarelo Álico com 21738,0ha. (63 \%), Podzólico Vermelho Amarelo Álico com 11064,4ha. (32\%), Solos Litólicos com 969.5ha. (3\%), Latossolo Amarelo Álico com 657.5ha. (2\%) e Solos Aluviais com 75.45ha. (0,2\%).Quanto à cobertura de solo, a área de contribuição da barragem é formada por Pasto: 20.075,64ha.; Mata Capoeira: 8.143,04ha.; Reflorestamento: 2.416,23ha.; Pasto Sujo: 2.183,00ha.; Pasto Degradado: 845,63ha.; Áreas Cultivadas: 249,50ha.; Solo Exposto: 212,09ha.; Reflorestamento Cortado: 185,92ha.; Corpos D'água: 84,80ha.; Atividades Minerais: 42,97ha.; Área Urbanizada: 31,34ha.; e, Área Degradada: 16,26ha. . O clima da região é do tipo úmido com verões quentes e invernos com média de $18^{\circ} \mathrm{C}$ (Cwa) segundo a classificação de Köeppen, com precipitações anuais média de 42\% do total ocorrendo no verão e apenas 7\% do total no inverno (FISCH, 1995).

\subsection{DESCRIÇÃO DOS MÉTODOS}

A base de dados para este estudo foi extraída do Banco de Dados Ambientais Georreferenciados da Bacia do Rio Una, previamente existente e descrito por Batista et al. (2005). Estes dados foram processados por meio do software de geoprocessamento SPRING disponível no Laboratório de Sensoriamento, Geoprocessamento e Informática Rural (LAGEO) no campus do Departamento de Ciências Agrárias da Universidade de Taubaté (UNITAU). Inicialmente, foi localizada nessa base de dados o ponto no rio onde seria

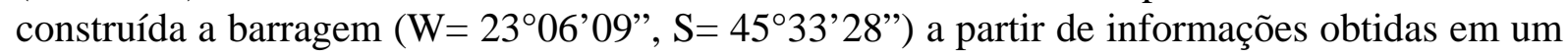
dos mapas do Plano Diretor do Município de Taubaté.

A partir da localização da barragem e do formato da represa no mapa foi escolhida a linha de cota de 645,0m como limite topográfico do espelho d’água a ser gerado pelo represamento. Uma vez delimitado o espelho, avaliou-se o balanço hídrico de Taubaté para a construção da represa no ribeirão Itaim.

Segundo Fisch (1995), o balanço hídrico é um método de estimativa da disponibilidade de água no solo que pode ser utilizado pelas plantas. Este fundamanta-se no princípio da conservação de massa e pode ser representado pela equação:

PREC + DEF - ETP - ARM - EXC $=0$

No qual PREC representa a precipitação mensal, ETP é uma estimativa da evapotranspiração potencial (no caso a utilizada foi a de Thornthwaite), DEF é o déficit hídrico, ARM é a variação do armazenamento de água no solo e EXC é o excesso de água. Todos os termos possuem unidade de milímetros de água. 
A metodologia do cálculo do balanço hídrico mais utilizada é a desenvolvida por Thornthwaite e Mather, que compara mês a mês, dados de precipitação e evapotranspiração potencial, considerando-se uma determinada capacidade de campo.

Para o balanço hídrico de Taubaté utilizou-se a série temporal de dez anos (19821992) de precipitação diária e a normal climatológica (temperatura e precipitação mensal) do Departamento Nacional de Meteorologia - DNMET e o Departamento de Águas e Energia Elétrica - DAEE.

Tabela I: Série temporal da Precipitação mensal (mm) na UNITAU (1982/1992)

\begin{tabular}{|c|c|c|c|c|c|c|c|c|c|c|c|c|c|}
\hline & J & F & M & A & M & J & J & A & S & O & N & D & ANO \\
\hline $\mathbf{1 9 8 2}$ & & & & & & & 53 & 95 & 15 & 146 & 142 & 230 & \\
\hline $\mathbf{1 9 8 3}$ & 258 & 193 & 137 & 112 & 128 & 151 & 53 & 12 & 266 & 52 & 109 & 158 & 1629 \\
\hline $\mathbf{1 9 8 4}$ & 104 & 63 & 67 & 109 & 91 & 0 & 4 & 49 & 85 & 25 & 99 & 161 & 887 \\
\hline $\mathbf{1 9 8 5}$ & 275 & 200 & 190 & 44 & 57 & 11 & 3 & 9 & 76 & 117 & 110 & 237 & 1329 \\
\hline $\mathbf{1 9 8 6}$ & 143 & 134 & 268 & 84 & 58 & 7 & 27 & 82 & 40 & 43 & 116 & 250 & 1252 \\
\hline $\mathbf{1 9 8 7}$ & 294 & 215 & 111 & 221 & 181 & 8 & 12 & 2 & 50 & 104 & 86 & 71 & 1355 \\
\hline $\mathbf{1 9 8 8}$ & 196 & 293 & 213 & 97 & 153 & 31 & 0 & 0 & 34 & 154 & 72 & 178 & 1421 \\
\hline $\mathbf{1 9 8 9}$ & 232 & 340 & 247 & 113 & 73 & 86 & 84 & 79 & 84 & 19 & 136 & 194 & 1687 \\
\hline $\mathbf{1 9 9 0}$ & 162 & 123 & 133 & 75 & 21 & 5 & 68 & 76 & 118 & 83 & 108 & 95 & 1067 \\
\hline $\mathbf{1 9 9 1}$ & 302 & 162 & 356 & 85 & 20 & 33 & 10 & 14 & 118 & 141 & 97 & 178 & 1516 \\
\hline 1992 & 167 & 130 & 160 & 80 & 54 & 0 & & & & & & & \\
\hline MÉDIA & 213 & 185 & 188 & 102 & 83 & 33 & 31 & 42 & 88 & 88 & 107 & 175 & \\
\hline SIGMA & 65 & 79 & 81 & 44 & 52 & 46 & 31 & 35 & 68 & 49 & 20 & 55 & \\
\hline MAX & 302 & 340 & 356 & 221 & 181 & 151 & 84 & 95 & 266 & 154 & 142 & 250 & \\
\hline MIN & 104 & 63 & 67 & 44 & 20 & 0 & 0 & 0 & 15 & 19 & 72 & 71 & \\
\hline
\end{tabular}

Fonte: FISCH, G. BIOCIÊNCIAS, Taubaté, v.1, n.1, p.89, jul. - dez. 1995.

Tabela II: Balanço hídrico de Thornthwaite para a cidade de Taubaté (SP). Valores em mm.

\begin{tabular}{|c|c|c|c|c|c|c|c|c|}
\hline MES & PREC & ETP & PREC-ETP & VAL & ARM & ETR & DEF & EXC \\
\hline JAN & 213 & 119 & 94 & 100 & 0 & 119 & 0 & 94 \\
\hline FEV & 185 & 103 & 82 & 100 & 0 & 103 & 0 & 82 \\
\hline MAR & 188 & 101 & 87 & 100 & 0 & 101 & 0 & 87 \\
\hline ABR & 102 & 75 & 27 & 100 & 0 & 75 & 0 & 27 \\
\hline MAI & 83 & 56 & 27 & 100 & 0 & 56 & 0 & 27 \\
\hline JUN & 33 & 43 & -10 & 90 & -10 & 43 & 0 & 0 \\
\hline JUL & 31 & 45 & -14 & 76 & -14 & 45 & 0 & 0 \\
\hline AGO & 42 & 59 & -17 & 59 & -17 & 59 & 0 & 0 \\
\hline SET & 88 & 72 & 16 & 75 & 16 & 72 & 0 & 0 \\
\hline OUT & 88 & 86 & 2 & 77 & 2 & 86 & 0 & 0 \\
\hline NOV & 107 & 94 & 13 & 100 & 13 & 94 & 0 & 0 \\
\hline DEZ & 175 & 11 & 64 & 100 & 10 & 11 & 0 & 54 \\
\hline ANO & 1335 & 964 & 371 & & 0 & 964 & 0 & 371 \\
\hline
\end{tabular}

Fonte: FISCH, G. BIOCIÊNCIAS, Taubaté, v.1, n.1, p.90, jul. - dez. 1995.

\section{RESULTADOS E DISCUSSÃO}

Com base no modelo numérico do terreno, usando-se o SPRING, foi feito o cálculo do volume da estimado represa que deve ser de $33.352 .252,28 \mathrm{~m}^{3}$ ou 33.352.252.280 litros, com uma profundidade média de 13,3m e máxima de 40m. 


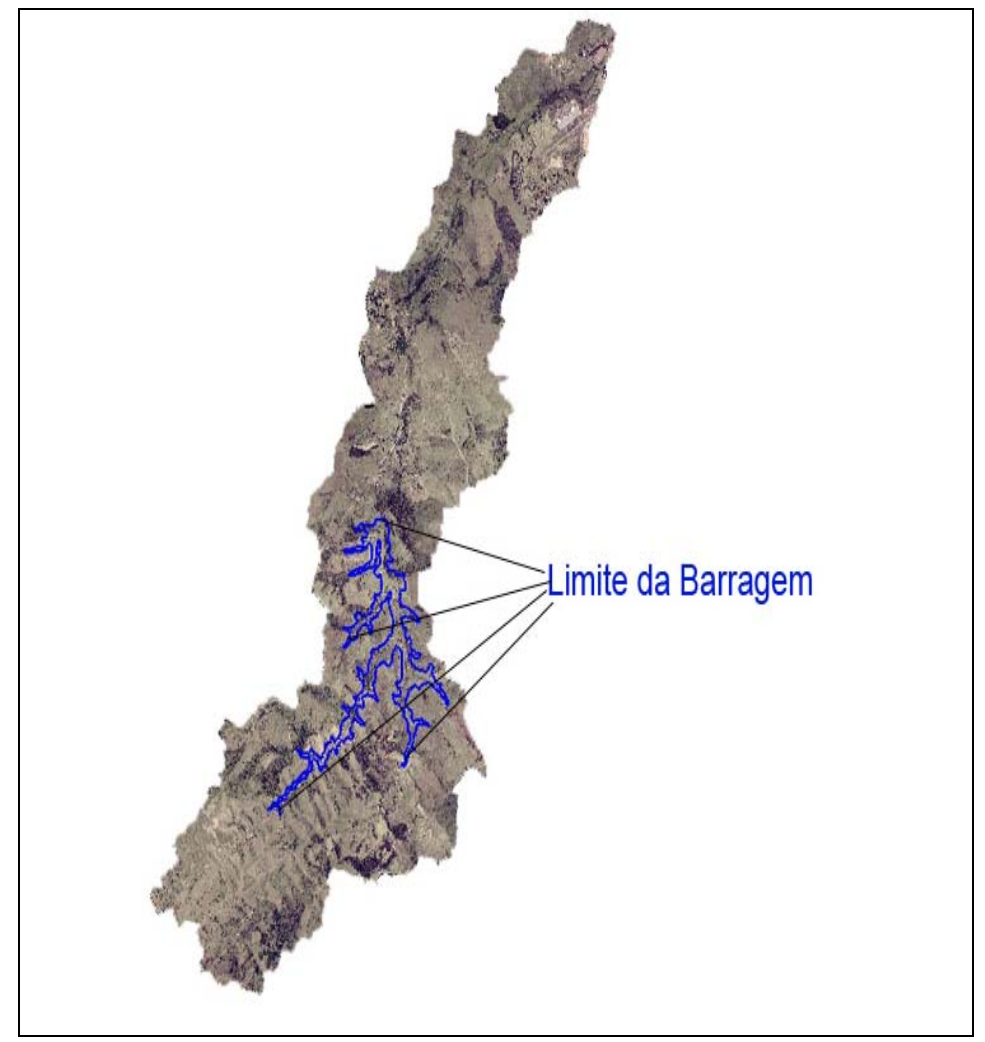

Figura 1. Localização dos limites do espelho d'água da represa em relação aos limites da bacia do ribeirão Itaim.

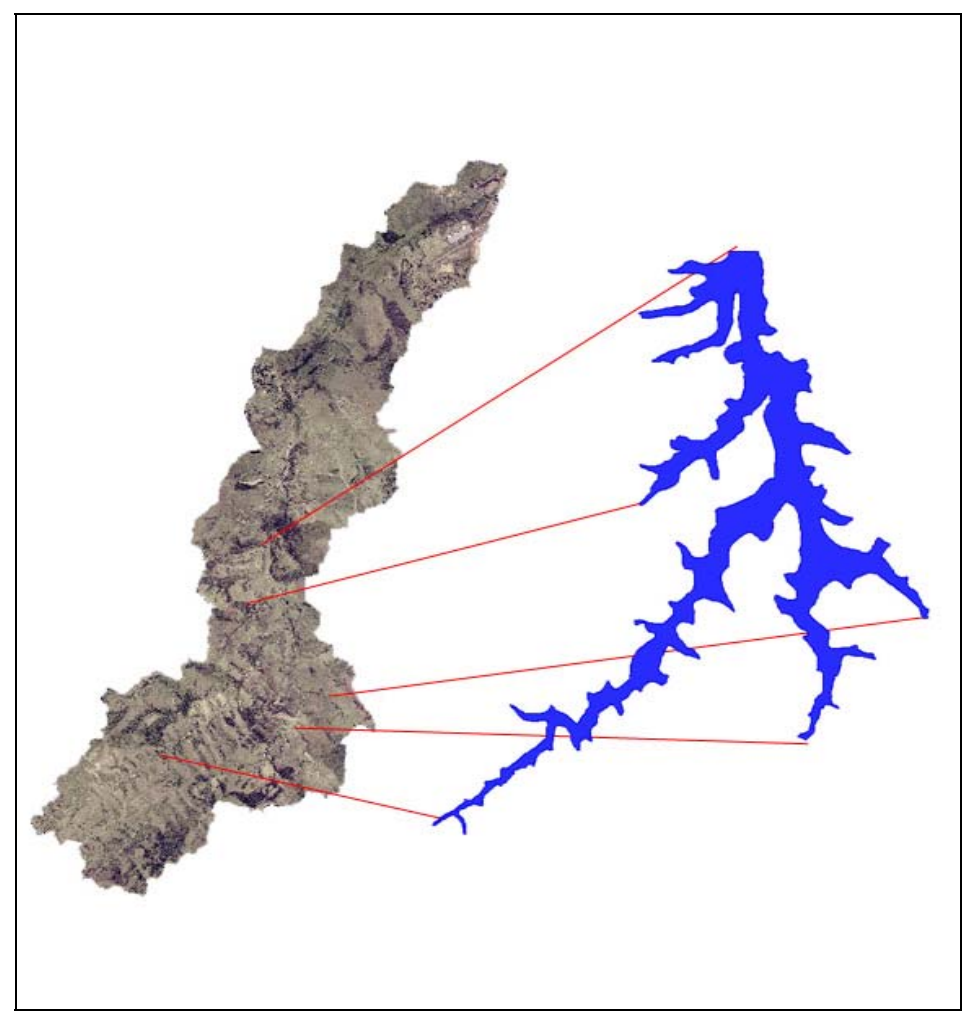

Figura 2. Detalhe do formato da área do espelho d’água que será gerado com a construção da barragem. 
A partir da delimitação da área a ser inundada foi pesquisada a vazão média do ribeirão do Itaim que é de $0,5 \mathrm{~m}^{3} / \mathrm{s}$, para assim determinar o tempo de inundação da represa do Ribeirão Itaim. Para obtenção desses resultados foram utilizados dados do balanço hídrico de Thornthwaite para a cidade de Taubaté, presente na pesquisa de Fisch (1995).

Segundo Fisch (1995), o total anual de precipitação foi calculado considerando o ano hidrológico (de Agosto de um ano a Julho do ano seguinte). Os anos de 82/83, 86/87 e 88/89 apresentaram-se como anos chuvosos (total anual acima de $15 \%$ do normal). Já os anos de 83/84, 84/85, 89/90 e 91/92, apresentaram precipitação um pouco inferior (menor que a 5\% a normal). É importante ressaltar que o extremo chuvoso de 82/83 (que apresentou 24\% acima da precipitação normal), foi marcado pela presença do evento El-Niño, que provoca chuvas mais intensas na região Sul e Sudeste do Brasil.

Ainda de acordo com Fisch, os resultados obtidos com o balanço hídrico mostram que o total anual médio de precipitação no período de dez anos foi de $1335 \mathrm{~mm}$, e o verão em Taubaté foi a estação mais chuvosa, com cerca de $42 \%$ do total anual, ao passo que o inverno foi seco, com apenas 7\%. Apesar da pouca precipitação nos meses de inverno, devido às baixas temperaturas, o consumo de água (ETP) não é elevado, de tal forma que não ocorre déficit hídrico.

Diante desses dados, foi calculado a precipitação mensal, a evapotranspiração potencial,o déficit hídrico, a variação do armazenamento de água no solo e o excesso de água na área necessários para a inundação da represa do Ribeirão Itaim. Chegando assim aos seguintes resultados: seriam necessários um ano e oitenta e quatro dias (ou 449 dias) com precipitação de 133,5mm, evapotranspiração de $96,4 \mathrm{~mm}$, défict hídrico de $0 \mathrm{~mm}$, variação do armazenamento de água no solo de $0 \mathrm{~mm}$ e excesso de água de $37,1 \mathrm{~mm}$, para o preenchimento da represa localizada na sub-bacia do ribeirão Itaim.

Tabela III - Cálculo do volume hídrico necessário para a inundação da sub-bacia do ribeirão Itaim

\begin{tabular}{|c|c|c|c|c|c|c|c|}
\hline $\begin{array}{c}\text { PREC } \\
(\mathrm{mm})\end{array}$ & $\begin{array}{c}\text { ETP } \\
(\mathbf{m m})\end{array}$ & $\begin{array}{c}\text { PREC-ETP } \\
\text { (mm) }\end{array}$ & $\begin{array}{l}\text { ARM } \\
\text { (mm) }\end{array}$ & $\begin{array}{l}\text { DEF } \\
(\mathrm{mm})\end{array}$ & $\begin{array}{l}\text { EXC } \\
(\mathrm{mm})\end{array}$ & $\begin{array}{c}\mathbf{Q} \\
\left(\mathrm{m}^{3} / \mathbf{s}\right)\end{array}$ & $\begin{array}{l}\text { TEMPO DE } \\
\text { INUDAÇÃO }\end{array}$ \\
\hline 133.5 & 96.4 & 37.1 & 0 & 0 & 37.1 & 0.5 & 1 ano e 84 dias \\
\hline
\end{tabular}

\section{CONSIDERAÇÃOES FINAIS}

Em uma construção de barragem podem ocorrer diversos tipos de impactos ambientais. Para que esse gerenciamento ambiental possa ser feito com mais eficiência é recomendável à utilização de um SIG - Sistema de Informações Geográficas. Dessa forma, pôde-se determinar a abrangência da lâmina d água e o volume necessário de chuva para inundar a represa. Além disso, esta ferramenta pode auxiliar na antecipação de problemas antes mesmo que a barragem seja construída, permitindo assim prever possíveis impactos econômicos e sociais no local.

\section{REFERÊNCIAS}

BATISTA, G. T.; TARGA, M. S.; DIAS, N. W.; CATELANI, C. S. Modelo de Banco de Dados Ambientais Georreferenciados Voltado à Recuperação e Preservação de Recursos Hídricos de uma Bacia de Médio Porte, o Modelo da Bacia do Rio Una, Paraíba do Sul, SP (P. 1-16).. In: XVI Simpósio Brasileiro de Recursos Hídricos, 2005, João Pessoa, PB. Anais do XVI Simpósio Brasileiro de Recursos Hídricos. Rio de Janeiro : ABRH, 2005. v. 1.

BRASIL. Lei Federal No 4.771, de 15 de setembro de 1965 (Institui o Novo Código Florestal Brasileiro), 1965. 
CARVAlHO, N. de O. - Hidrossedimentologia Prática - CPRM - Rio de Janeiro, 1994.

CATELANI, C. S.;. Batista, G. T. 2006. Geotecnologias aplicadas à virtualização de terreno como ferramenta para a realização de estudos ambientais em bacias hidrográficas. Estudo de caso para implantação de um reservatório na bacia do Rio Una. Artigo apresentado no PRIMEIRO SEMINÁRIO DE SENSORIAMENTO REMOTO E GEOPROCESSAMENTO PARA ESTUDOS AMBIENTAIS NO VALE DOPARAÍBA GEOVAP 2006, 07 de dezembro, Universidade de Taubaté, Taubaté, São Paulo, Brasil. Disponível em http://www.agro.unitau.br/soac/viewabstract.php?id=27\&cf=1 - Acesso em $15 / 07 / 2009$

CONAMA, Resolução no 303 de 20 de março de 2002. Dispõe sobre

Parâmetros, definições e limites de Áreas de Preservação Permanente, 2002.

COOPERATIVA DE SERVIÇOS PESQUISAS TECNOLOÓGICAS E INDUSTRIAIS CPTI. Plano de Bacias Hidrográficas do Rio Paraíba do Sul e Serra da Mantiqueira. Relatório Final. São Paulo 2000. CD-ROM.

Decreto $\mathbf{n}^{0}$. 87.561 de 13/09/1982. Rio Paraíba do Sul - dispõe sobre medidas de recuperação e proteção ambiental da bacia hidrográfica da bacia hidrográfica do rio Paraíba do Sul.

FISCH, G. Caracterização climática e balanço hídrico de Taubaté (S.P). Revista Biociências, v. 1, n.1, p. 81-90, 1995.

Lei $\mathbf{N}^{\mathbf{0}} \mathbf{. 7 7 5 4 / 1 9 8 9}$ - "Estabelece medidas para proteção das florestas existentes nas nascentes dos rios e dá outras providências." - Data da legislação: 14/04/1989 - Publicação DOU, de 18/04/1989.

PMT. Plano Diretor Municipal de Taubaté, 2006, Taubaté- - SP. http://www.taubate.sp.gov.br/plano_diretor/plan_dir.htm>. Acesso em 20/08/2009

SANTOS, R.R. Abordagem ambiental preliminar e qualidade das águas da Bacia do Rio Uma no período de estiagem. Taubaté 2003 68p. Dissertação de Mestrado da Universidade de Taubaté 2003. 